\title{
NOTAS SOBRE NEÓFITAS 4. POLYGONUM NEPALENSE (POLYGONACEAE), UNA PLANTA INVASORA NUEVA PARA MÉXICO
}

\author{
Heike Vibrans ${ }^{1}$ y Ana María Hanan Alipi ${ }^{2}$
}

${ }^{1}$ Colegio de Postgraduados, Campus Montecillo, Programa de Botánica, km 36.5 carretera México-Texcoco, 56230 Montecillo, Texcoco, México. heike@colpos.mx ${ }^{2}$ Universidad Autónoma de Nayarit, Unidad Académica de Agricultura, Programa de Biología, Km 9 Carretera Tepic-Compostela, Xalisco, Nayarit, México.

\section{RESUMEN}

Se registra como nuevo para México a Polygonum nepalense Meisn. (= Persicaria nepalensis (Meisn.) H. Gross), familia Polygonaceae, originario de Asia. Se encontraron dos poblaciones en las partes altas del Estado de México, que tienen el aspecto de estar en expansión. Se trata de una maleza agresiva, peligrosa para varios cultivos y también invasora de la vegetación natural. Dado que su irrupción parece ser reciente e incipiente, se sugieren esfuerzos para erradicar la especie.

Palabras clave: Estado de México, invasora, maleza, Persicaria nepalensis, Polygonum nepalense.

\section{ABSTRACT}

Polygonum nepalense Meisn. (= Persicaria nepalensis (Meisn.) H. Gross), Polygonaceae, of Asia is reported as new to Mexico. Two populations were found in high-altitude areas of the State of Mexico, and they appear to be in expansion. The species is known as an aggressive weed, with high impact on various crops, and also as an invader of natural vegetation. As the invasion seems to be recent and incipient, an eradication effort is recommended. weed.

Key words: State of Mexico, invasive, Persicaria nepalensis, Polygonum nepalense,

Exploraciones botánicas recientes hechas para un proyecto de flora digital de las malezas de México (www.malezasdemexico.net) han dado como resultado el 
registro de una planta invasora hasta ahora desconocida para México: Polygonum nepalense Meisn. (= Persicaria nepalensis (Meisn.) H. Gross). Dos poblaciones de esta especie se localizaron en las partes altas del Estado de México. Se le encontró por primera vez en otoño de 2005 en un cultivo de maíz al oeste del volcán Nevado de Toluca. El segundo rodal grande se halló en octubre de 2006 entre Ocoyoacac y Santiago Tianguistenco en el Valle de Toluca, en las faldas del volcán El Quilotzi, en sembradíos de maíz, así como en los terrenos en descanso adyacentes y orillas de barrancas.

Se trata de una representante asiática de Polygonum con un hábito muy distinto al de las especies conocidas en el país. Se le registra como maleza agresiva en otras partes del mundo.

Polygonum nepalense es una hierba anual, de $20-40 \mathrm{~cm}$, con tallos algo carnosos, flojos, decumbentes o ascendentes, ramificados y enraizando en los nudos. Las hojas inferiores tienen pecíolos alados de 2-3 cm de largo. Las láminas son ovadas a triangulares, de 3-5 por 2-4 cm, ambas superficies esparcidamente estrigosas o glabras, con puntos minúsculos amarillentos. La base de la hoja es ampliamente cuneada y decurrente a lo largo del pecíolo, formando el ala; el margen es entero. Las hojas superiores son más pequeñas, con un pecíolo más corto o sin él; pueden ser subsésiles o amplexicaules. La ocrea es tubular, de color café, de 5-10 mm de largo, membranácea, con el ápice cortado en forma oblicua, no ciliado, con algunas setas reflejas en la base. La inflorescencia consiste de cimas monocasiales, que forman un seudocorimbo muy denso, llevando en la base una hoja involucral. El pedúnculo es largo, con pelos glandulares y con brácteas ovado-elípticas. Los pedicelos son más cortos que las brácteas. El perianto es de color rosa a blanco, a veces hasta rojo-púrpura (en los ejemplares de México sólo se encontró perianto blanco), y generalmente consiste de 4 tépalos. Éstos son oblongos, de 2-3 mm de largo, y obtusos. Los estambres son 5-8, tan largos como los tépalos; las anteras son purpúreas a negras. Los estilos son 2-3, fusionados en la base, con estigmas capitados. Los aquenios permanecen dentro del perianto seco, son negros, opacos, anchamente ovoides, biconvexos, de 2.0-2.5 mm de largo, con abundantes depresiones en sus superficies.

El hábito, detalles y aspectos de las poblaciones se muestran en la figura 1. La descripción se basa en Li Anjen et al. (1998).

Material examinado: Estado de México: Municipio Temascaltepec, carretera Toluca-Tejupilco, poco antes de San Francisco Oxotitlán, campos de cultivo y bosque de pino; en un cultivo de maíz ya cosechado, $19^{\circ} 09^{\prime} 01.2^{\prime \prime} \mathrm{N}, 99^{\circ} 54^{\prime} 03.6^{\prime \prime} \mathrm{W}$; altitud: 2630 m, 5.XI.2005, Vibrans 7873 (CHAPA, MEXU). Municipio Capulhuac, 


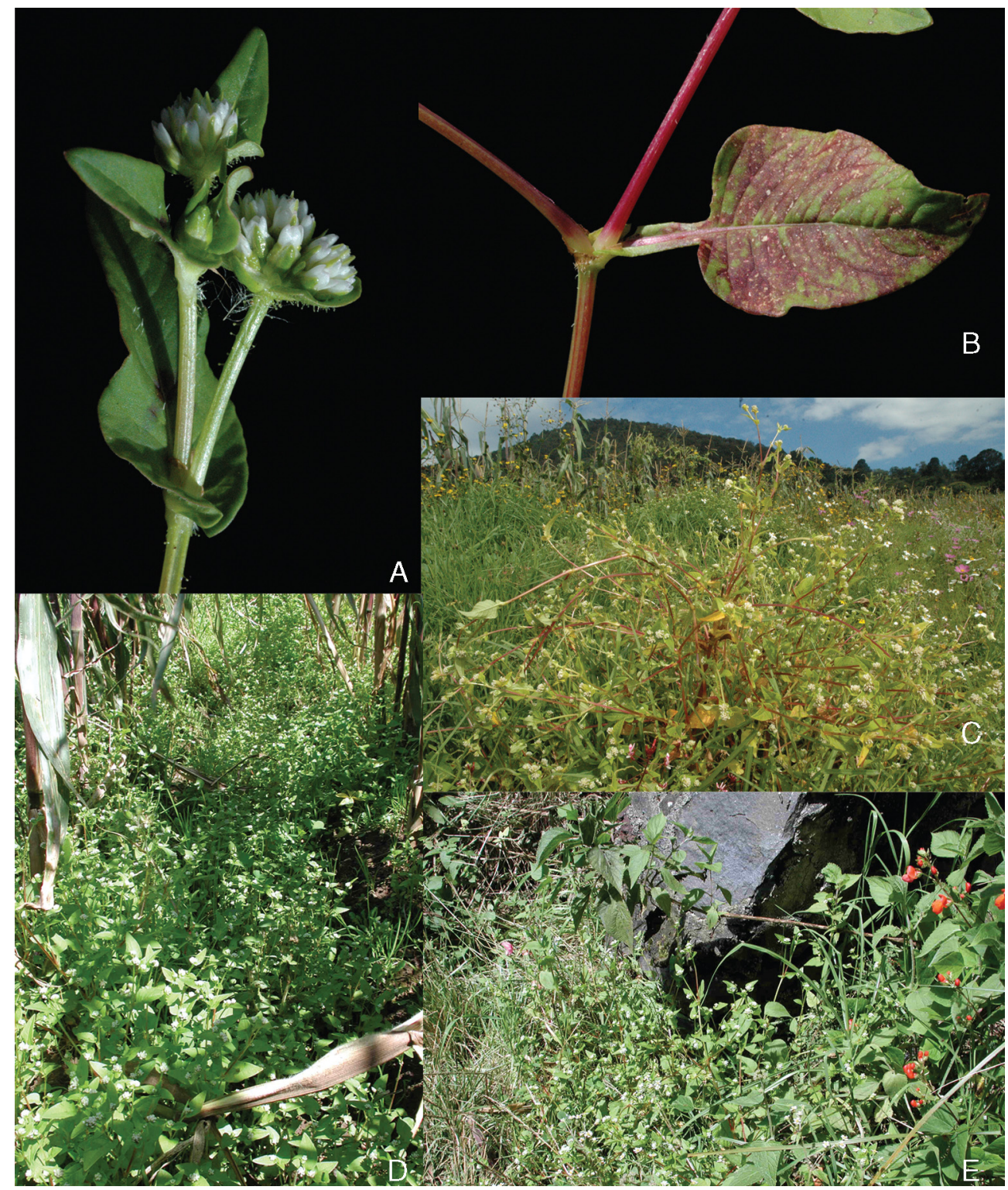

Fig. 1. A. inflorescencia de Polygonum nepalense; B. hoja con pecíolo alado; C. hábito de la planta; D. Polygonum nepalense formando poblaciones densas en un cultivo de maíz; E. la especie creciendo en vegetación nativa (en la esquina inferior derecha Phaseolus coccineus). Las fotografías A, B y C son de Pedro Tenorio Lezama; D y E son de Heike Vibrans. Se tomaron el 6 de octubre de 2006 en el sitio de la población de Tlazala, Estado de México, mencionada en el texto. 
carretera Santiago Tianguistenco-Ocoyoacac, desviación a Tlazala, a aproximadamente $1 \mathrm{~km}$ del crucero, brecha que va a un panteón, atrás de un cerro, en las faldas del volcán Quilotzi, 19¹2'57.7" N, 99²7'30.5" W, altitud: 2606 m, 6.X.2006, Vibrans 8036 (CHAPA, MEXU).

$P$. nepalense se puede distinguir de las demás especies de Polygonum de México por sus hojas anchas y sus flores agrupadas en seudocorimbos densos, semejando cabezuelas casi esféricas que llevan en la base una hoja involucral grande.

Según la información de una persona local de Tlazala, la planta llegó hace poco tiempo (en el año 2004) a la región y se ha extendido muy rápidamente. En la actualidad se encuentra en varias hectáreas de cultivos y tierra en descanso, pastizales y en la orilla de barrancas entre rocas, formando poblaciones grandes y en parte dominantes.

La especie se encuentra ampliamente distribuida en Asia, desde Afganistán hasta China y las Filipinas, pasando por India, Tailandia e Indonesia. También existe en África tropical.

Se registran naturalizaciones locales en varios sitios en Europa (Diekjobst, 1994). En Norteamérica se conoce de Columbia Británica en Canadá, de Connecticut, Massachussetts, Florida, Pennsylvania y el estado de Nueva York en E.U.A. (Hinds y Freeman, 2005). También se encuentra naturalizada en las partes altas de algunos países de Sudamérica, en particular de Ecuador, Colombia y Venezuela (Meier, 2006). Su nombre en inglés es Nepalese smartweed.

Se presenta generalmente en condiciones de alta humedad y fertilidad. En Pakistán es una de las especies de Polygonum más comunes. Crece sobre todo a lo largo de canales de riego, en sitios sombreados y entre rocas (Qaiser, 2001). Es importante como maleza en cultivos hortícolas, pero también se registra de arroz, maíz, papa, café, de viveros y como invasiva en la vegetación natural, por ejemplo la de alta montaña, bosques templados húmedos, orillas de ríos y pantanos (véase el resumen en Meier, 2006). El mencionado autor describe de la siguiente manera las poblaciones en Venezuela: “... en algunos cultivos se convirtieron en una verdadera plaga. En San Francisco de Galipán esta especie está ahogando los cultivos de fresa ... está compitiendo con diferentes cultivos, cubriendo los barbechos y formando alfombras en las plantaciones de eucalipto."

En las regiones intertropicales se encuentra generalmente en altitudes superiores a los $1000 \mathrm{~m}$, con el mejor desarrollo alrededor de los 2000-2500 m, pero llegando en las altas montañas a 3500 m (en Pakistán) y 3300 m en los páramos de 
Ecuador. En China llega a crecer a 4000 m (Li Anjen et al., 1998), pero en E.U.A. solamente hasta los 900 m s.n.m. En Pakistán florece de junio a septiembre; de China se registra la floración de mayo a agosto y la fructificación de junio a octubre.

Las poblaciones encontradas en México se comportan de acuerdo con esta vinculación ecológica, se encuentran en sitios altos, relativamente húmedos y en cultivos de surco; forman tapetes dentro de las milpas y colonizan la vegetación adyacente más o menos natural, incluyendo el pastizal y las orillas de barrancas. La planta también se ajusta al patrón fitogeográfico: la familia Polygonaceae es una de las que contienen una proporción elevada de especies exóticas en México (Villaseñor y Espinosa-García, 2004).

Las Polygonaceae frecuentemente se dispersan por medio de pájaros pero no se dispone de datos concretos sobre la propagación natural de Polygonum nepalense. Se ha registrado la dispersión de esta especie a larga distancia en el alimento comercial para aves (Meier, 2006), y ciertamente de este modo pudo ocurrir su introducción a México, pero no existen indicaciones concretas.

Las hojas y los brotes jóvenes son comestibles, pero tienen un sabor agrio. Según Meier (op. cit.), la planta no es consumida por el ganado; en Colombia incluso se le considera tóxica, y se le conoce con el nombre común de "barbasco mataganado". Es posible que contenga oxalatos, pero no se encontraron referencias al respecto. Se utiliza en la medicina tradicional china e hindú.

En los sitios donde se encontró en el Estado de México en la actualidad probablemente no hace mucho daño económico directo, ya que los cultivos de maíz de la región se llevan a cabo con métodos que toleran cierta cobertura de malezas en la segunda mitad del ciclo. Pero Polygonum nepalense sustituye las plantas arvenses locales, que son principalmente nativas y se usan como forraje. De allí cabe deducir que si este elemento adventicio realmente es tóxico, entonces puede ser causa de pérdidas.

Se considera que el principal peligro consiste en que la especie llegue a sembradíos de menor estatura y más intensivos que el del maíz, como por ejemplo los de plantas ornamentales en el mismo Estado de México o en Xochimilco, o de hortalizas y fresas en varias regiones de México, en particular el Bajío. Tiene potencial para causar graves daños a tales cultivos por competencia y posiblemente requiera de modificaciones en los métodos de combate. Es difícil de exterminar porque forma semillas rápidamente. Además, dado que la especie se encuentra cuarentenada en varios países, entre ellos en Australia, puede afectar las exportaciones tanto de plantas ornamentales como de granos. 
Se propone que se investigue a la brevedad posible la fuente de semillas de estos dos brotes descritos, así como la distribución precisa de la especie en la región, y que se inicie una campaña de erradicación sostenida.

\section{AGRADECIMIENTOS}

La Secretaría de Medio Ambiente y Recursos Naturales financió el trabajo de campo y de herbario (SEMARNAT 2004-C01-00405). A Pedro Tenorio Lezama se agradecen sus excelentes fotografías, y al Herbario Nacional el apoyo que su personal ha prestado al proyecto. Especialmente se reconoce su política de mantener colecciones de todas partes del mundo, las cuales son la herramienta indispensable para la identificación de especies de nueva introducción al país.

\section{LITERATURA CITADA}

Diekjobst, H. 1994. Der nepalesische Knöterich (Polygonum nepalense Meisn.), ein Neufund in Deutschland. Flor. Rundbr. 27(2): 90-93.

Hinds, H. R. y C. C. Freeman. 2005. Persicaria. In: Editorial Committee (eds). Flora of North America. 1993+ Flora of North America North of Mexico. 12+ vols. New York y Oxford. Vol. 5. Disponible en la red: http://www.efloras.org/florataxon.aspx?flora id $=1 \&$ taxon $\mathrm{id}=242100103$.

Li, A., B. Bao, A. E. Grabovskaya-Borodina, S. Honh, J. McNeill, S. L. Moskayin, H. Ohba \& C. Park. 2003. Polygonaceae. Flora of China 5: 278-315. http://flora.huh.harvard. edu/china/mss/volume05/Polygonaceae.pdf

Meier, W. 2006. Contribución al conocimiento de Persicaria nepalensis (Meisn.) H. Gross y P. capitata (Buch.-Ham. ex D. Don) H. Gross, especies invasoras en el Parque Nacional El Ávila, Venezuela. Acta Bot. Venez. 29(1): 1-16.

Qaiser, M. 2001. Polygonaceae. Flora of Pakistan. 205: 1-190. http://www.efloras.org/ florataxon.aspx?flora_id $=5 \&$ taxon_id=10717

Villaseñor, J. L. y F. J. Espinosa-García. 2004. The alien flowering plants of Mexico. Diversity and Distributions 10(2): 113-123. 